Nova Southeastern University

Florida

NOVA SOUTHEASTERN

UNIVERSITY

NSUWorks

Marine \& Environmental Sciences Faculty Articles Department of Marine and Environmental Sciences

$2-1-2000$

\title{
Horizontal Structure of the Upper Ocean Velocity and Density Fields in the Western Equatorial Pacific Warm Pool: Depth Range from 20 to $250 \mathrm{~m}$
}

Alexander Soloviev

Nova Southeastern University, soloviev@nova.edu

Roger Lukas

University of Hawaii - Manoa

Peter Hacker

University of Hawaii - Manoa

Find out more information about Nova Southeastern University and the Halmos College of Natural Sciences and Oceanography.

Follow this and additional works at: https://nsuworks.nova.edu/occ_facarticles

Part of the Marine Biology Commons, and the Oceanography and Atmospheric Sciences and Meteorology Commons

\section{NSUWorks Citation}

Alexander Soloviev, Roger Lukas, and Peter Hacker. 2000. Horizontal Structure of the Upper Ocean Velocity and Density Fields in the Western Equatorial Pacific Warm Pool: Depth Range from 20 to 250 m .Journal of Physical Oceanography, (2) : 416 -432.

https://nsuworks.nova.edu/occ_facarticles/634. 


\title{
Horizontal Structure of the Upper Ocean Velocity and Density Fields in the Western Equatorial Pacific Warm Pool: Depth Range from 20 to 250 m*
}

\author{
AleXANDER SOLOVIEV \\ Oceanographic Center, Nova Southeastern University, Dania, Florida \\ Roger Lukas ANd Peter Hacker \\ School of Ocean and Earth Science and Technology, University of Hawaii at Manoa, Honolulu, Hawaii
}

(Manuscript received 4 May 1998, in final form 8 April 1999)

ABSTRACT

\begin{abstract}
Wavenumber spectra of velocity and density fields in the western equatorial Pacific warm pool on scales 6-120 km are estimated using the shipboard survey data collected during the TOGA Coupled Ocean-Atmosphere Response Experiment (COARE). The spectra are averaged over three depth intervals: 20-60, 60110, and 110-250 m (corresponding to the Yoshida jet, the South Equatorial Current, and the southern edge of Equatorial Undercurrent). The velocity spectra are corrected for the mean flow shear advection, which is important under conditions of low gradient Richardson number (Ri). After that, both velocity and density spectra are consistent with an internal wave spectral model including a random component (equatorial version of the Garrett and Munk spectrum) and a tidal component (the Feng et al. tidal model). Tidal peaks, previously found by other COARE investigators as being prominent on the "moored" spectra (i.e., on the spectra derived from mooring data), appear to be much less significant on the "towed" spectra (i.e., on the spectra derived from shipboard surveys). The model and observations reveal some directional anisotropy of the towed velocity spectra depending on Ri.
\end{abstract}

\section{Introduction}

The spatial variability of the upper ocean in the warm pool area is an important factor in modeling the El Niño-Southern Oscillation climate cycle (Webster and Lukas 1992). The temperature anomalies in the warm pool area affect the global atmospheric circulation and its predictability. One reason is that the penetrative convection in the atmosphere is associated with the surface temperature anomalies. Moore and Kleeman (1996) found that numerical forecast errors can grow rapidly due to the release of energy associated with penetrative convection anomalies in the atmosphere. A proper choice of the statistical model of spatial variability of the upper ocean is also important for optimal interpolation and assimilation of the Coupled Ocean-Atmosphere Response Experiment (COARE) datasets.

Huyer et al. (1997) and Richards and Pollard (1991)

* SOEST Contribution Number 4927.

Corresponding author address: Dr. Alexander V. Soloviev, Oceanographic Center, Nova Southeastern University, 8000 North Ocean Drive, Dania, FL 33004-3078.

E-mail: soloviev@ocean.nova.edu reported large spatial and temporal variability in temperature and salinity in the upper ocean of the western equatorial Pacific. They observed frontal features with temperature differences of $1^{\circ} \mathrm{C}$ extending from the surface down to a depth of $150 \mathrm{~m}$, a strong salinity front associated with a surface convergence, and interleaving of high- and low-salinity waters in 10-m-thick layers that extend for several hundred kilometers in the northsouth direction. The velocity field in the upper $100 \mathrm{~m}$ of the ocean within the warm pool area is also strongly variable in time, forced by tidal forces, buoyancy fluxes, local winds, and, presumably, by remote winds (Lukas et al. 1995; Picaut et al. 1995; Pinkel et al. 1997).

The aim of this study is to determine the statistics of horizontal variability of density and velocity fields in the warm pool area on length scales from 6 to $120 \mathrm{~km}$ within the depth range $20-250 \mathrm{~m}$. For statistical analysis, we will use the data from shipboard (R/V Wecoma) and mooring (WHOI mooring) observations acquired during the COARE Intensive Observation Period (IOP) by Huyer et al. (1997), Lukas et al. (1995), and Plueddemann et al. (1993).

The paper is organized as follows. After a brief description of the data (section 2) and hydrometeorological conditions in the equatorial warm pool area (section 3), we substantiate our method of wavenumber spectral 
analysis in section 4. On scales from 6 to $120 \mathrm{~km}$, the horizontal variability of the upper ocean in the warm pool area can be caused by internal inertial-gravity waves, internal tidal waves, fronts, intrusions, eddies, and atmospheric forcing. Section 5 will demonstrate that the internal waves can account for most of the observed horizontal variability in the density and velocity fields (other processes than internal waves are briefly discussed in section $5 \mathrm{c}$ ).

\section{Data description}

The Coupled Ocean-Atmosphere Response Experiment was conducted in the western equatorial Pacific Ocean to obtain a better understanding of the warm pool system (Webster and Lukas 1992). This experiment included a four-month intensive observation period from November 1992 through February 1993. Most of the oceanographic and meteorological measurements were taken in the Intensive Flux Array (IFA) centered at $1^{\circ} 45^{\prime} \mathrm{S}, 156^{\circ} \mathrm{E}$. As a part of COARE IOP, the R/V Wecoma conducted three survey cruises during the following time periods: 13 November-2 December 1992, 18 December-9 January 1993, and 27 January-15 February 1993; each cruise included measurements of temperature, salinity, and velocity distribution in the upper $300 \mathrm{~m}$ of the ocean and continuous meteorological measurements of wind, air temperature, humidity, etc. (Huyer et al. 1997). The vessel repeated a butterfly pattern, centered near the Woods Hole Oceanographic Institution (WHOI) surface mooring, every 1.5 days over a 130 by $130 \mathrm{~km}$ polygon with the crossover point at $1.8^{\circ} \mathrm{S}$, $156.1^{\circ} \mathrm{E}$ (Fig. 1). A schematic diagram of the R/V Wecoma and measurements is shown in Fig. 2.

Velocity observations (Lukas et al. 1995) with a 150$\mathrm{kHz}, \mathrm{RD}$ Instruments acoustic Doppler current profiler were made almost continuously along the standard butterfly track within the IFA during all three COARE IOP legs of the R/V Wecoma. Dual GPS receivers were used to determine ship heading and to correct for gyro heading errors. The nominal depth range of observations was 18-300 m. Vertical resolution was nominally $8 \mathrm{~m}$, from data within $8-\mathrm{m}$ bins with 16-m pulse length (in leg 1) or 8-m pulse length (in legs 2 and 3). Ensemble averaging time interval is $2 \mathrm{~min}$. The velocity observations are accurate to better than $2 \mathrm{~cm} \mathrm{~s}^{-1}$ on horizontal scales greater than $10 \mathrm{~km}$. Repeat transport calculations around the closed survey segments indicate that current biases are less than $1 \mathrm{~cm} \mathrm{~s}^{-1}$. The shipboard ADCP measurements were averaged into $10-\mathrm{m}$ depth bins and gridded with approximately $3-\mathrm{km}$ horizontal spacing for the west-to-east and north-to-south legs and 2.1-km horizontal spacing for the south-to-west and east-to-north legs, using the CODAS software (Firing et al. 1995). The ADCP velocity spectra will be corrected to account for the block averaging.

During each of three cruises, the R/V Wecoma sampled repeatedly along the butterfly pattern (Fig. 1) with a towed undulating vehicle, SEASOAR, equipped with a conductivity-temperature-depth unit (Huyer et al. 1997). The SEASOAR towing speed was 7-8 knots. Minimum and maximum sampling depths were usually less than $3 \mathrm{~m}$ and more than $270 \mathrm{~m}$, respectively. The SEASOAR profiles were gridded with a $2-\mathrm{m}$ vertical resolution and with approximately $3-\mathrm{km}$ horizontal spacing for the west-to-east and north-to-south legs and with a $4.2-\mathrm{km}$ horizontal spacing for the south-to-west and east-to-north legs.

Some of the Wecoma sections included ship stops and changes of the course on technical and logistical reasons. The corresponding segments are excluded from the analysis.

In this work, we will also use the data from the WHOI mooring that was deployed in the center of the intensive flux array $\left(1.75^{\circ} \mathrm{S}, 156^{\circ} \mathrm{E}\right)$ for the duration of the intensive observation period. The WHOI mooring was equipped with velocity and temperature sensors in the upper $300 \mathrm{~m}$ of the water column (Plueddemann et al. 1993; Weller and Anderson 1996). In our analysis, we will use the data from the velocity sensors located at 19-m and 52.5-m depth.

To ensure that the Wecoma ADCP and the WHOI current meters produce compatible measurements, the interpolated values of $u$ and $v$ are calculated at crossing the buoy's longitude (actually there was $\sim 0.05$ deg difference on latitude). The towed and moored velocity data correspond to each other at the intersections. For all Wecoma COARE IOP-2 leg, for example, the mean differences between the ship and mooring velocity data, calculated at the intersections, are as low as $-0.013 \mathrm{~m}$ $\mathrm{s}^{-1}$ for $u$ and $0.016 \mathrm{~m} \mathrm{~s}^{-1}$ for $v$.

\section{Meteorological and hydrological conditions}

The three Wecoma survey cruises within the COARE IOP involved a variety of the weather conditions (Huyer et al. 1997; Weller and Anderson 1996). Just prior to the first Wecoma survey, there had been a prolonged burst of moderate westerlies in late October and early November. During the first survey period, winds were generally weak with net surface heating and little rainfall (the calm weather conditions were interrupted by a brief burst of moderate westerlies on 24-25 November). Low winds and net heating continued until 12 December when there was another burst of moderate westerly winds that, however, ended a few days before the beginning of the second survey period. A series of three strong westerly wind bursts occurred between 20 December and 3 January, coinciding with the first half of the second survey period. These wind bursts were followed by calm winds and frequent rain events. Between the second and third survey periods, winds were generally from the southeast, that is, favorable for equatorial upwelling (Huyer et al. 1997). Westerly winds resumed on 27 January, coinciding with the beginning of the third survey period. Moderate westerly winds with frequent 


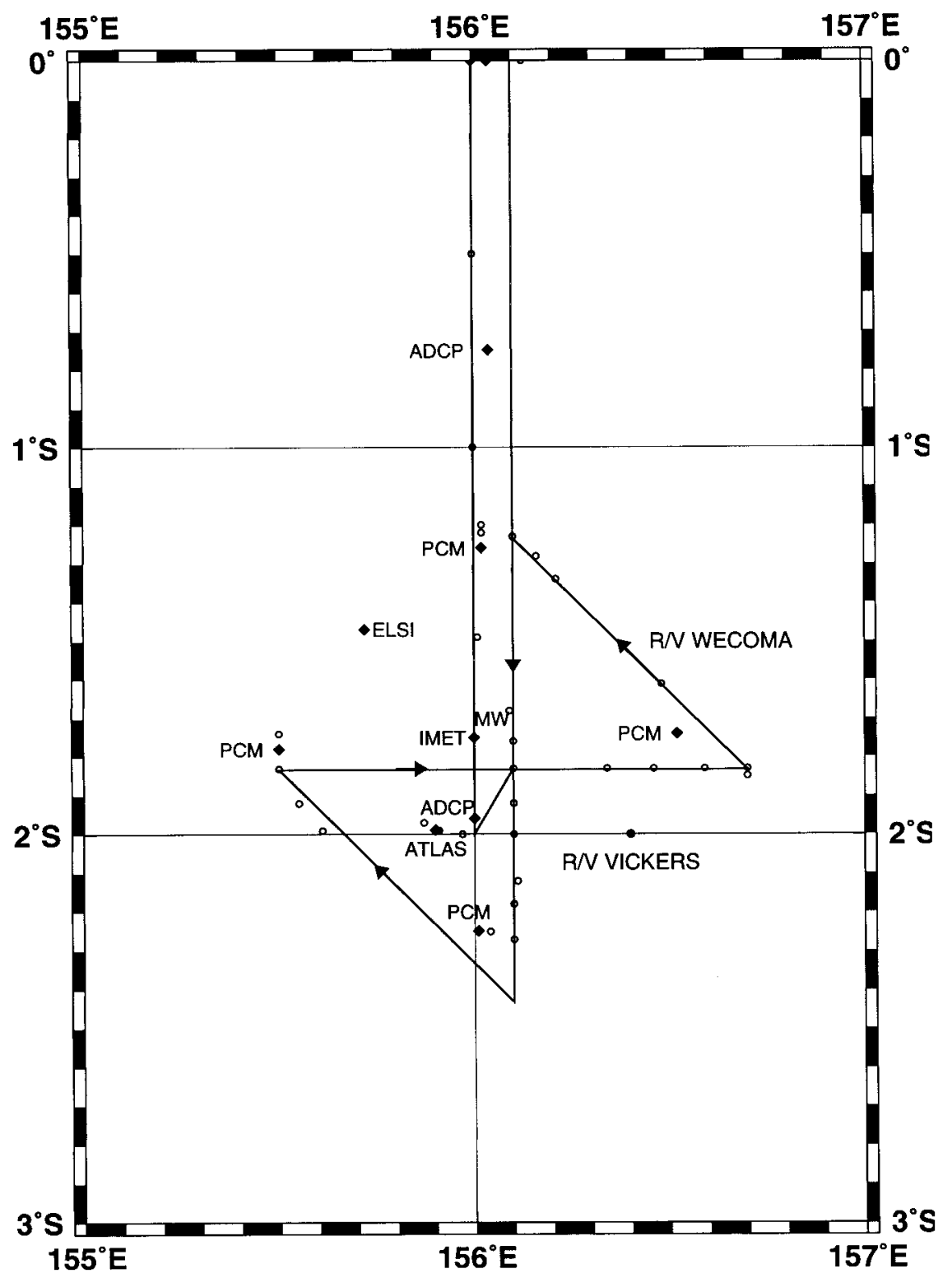

FIG. 1. Butterfly survey pattern of the R/V Wecoma in the TOGA COARE Intensive Flux Array. Details of measurements from COARE moorings ADCP, PCM, ELSI, IMET, and ATLAS and from the R/V Vickers and the R/V Moana Wave (MW) can be found in Webster and Lukas (1992).

strong squalls prevailed during the third survey cruise of the R/V Wecoma.

According to analysis of Huyer et al. (1997), typical hydrological features of the western equatorial Pacific warm pool include

a very warm and relatively fresh surface layer, with temperatures $>28.5^{\circ} \mathrm{C}$ and salinity decreasing northward; a very sharp thermocline with temperature decreasing from $\sim 28^{\circ} \mathrm{C}$ at $\sim 50 \mathrm{~m}$ to $\sim 12^{\circ} \mathrm{C}$ at $\sim 250 \mathrm{~m}$ and intermediate isotherms diverging northward toward the equator to envelop the core of the Equatorial Undercurrent at $\sim 175$ m; a subsurface salinity maximum, consisting of a northward-tending tongue of high-salinity South-Pacific water; and a deep vertically mixed layer, $\sim 50 \mathrm{~m}$ thick, with a temperature of $\sim 12^{\circ} \mathrm{C}$ and salinity of $34.8 \mathrm{psu}$, corresponding to the equatorial thermostad.

Figures 3 and 4 show the ensembles of hydrophysical parameters averaged over the R/V Wecoma individual sections (light lines) as well as the averages (bold lines) and standard deviations (thin lines) over all three cruises. The mean velocity structure within the IOP array was dominated by reversals of current with depth (Figs. 


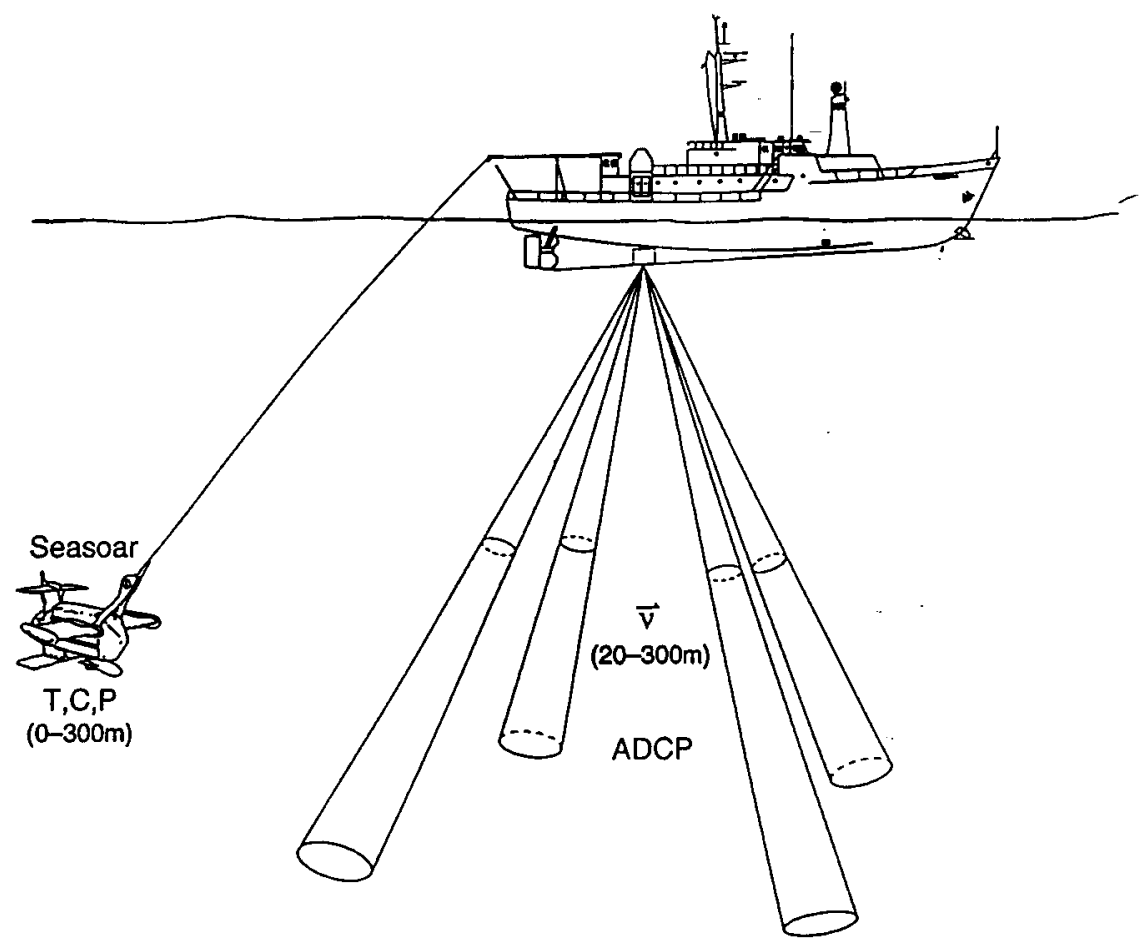

FIG. 2. Schematic diagram of R/V Wecoma and measurements. Wecoma was equipped with shipboard acoustic Doppler current profiler (ADCP). SEASOAR was towed behind the ship (see details in Huyer et al. 1997). The ship was also equipped by a meteorological MIDAS package and a bow-mounted CTD system (Wijesekera et al. 1999).

3d,e). According to Lukas et al. (1995), the surface layer extended to an average depth of $60 \mathrm{~m}$, flowing eastward at speeds up to $20 \mathrm{~cm} \mathrm{~s}^{-1}$ near the surface. The second layer extends from 60 to $110 \mathrm{~m}$, flowing westward at up to $10 \mathrm{~cm} \mathrm{~s}^{-1}$. The third layer is the southern edge of the Equatorial Undercurrent, which flowed eastward at up to $30 \mathrm{~cm} \mathrm{~s}^{-1}$ from $110 \mathrm{~m}$ to about $250 \mathrm{~m}$. These three layers can be associated with the Yoshida jet, the South Equatorial Current, and the southern edge of the Equatorial Undercurrent correspondingly. More details can be found in Lukas et al. (1995) and in Huyer et al. (1997).

\section{Horizontal variability}

Huyer et al. (1997) noticed the lateral homogenization of 20-dbar density and velocity fields in the warm pool area under conditions of westerly wind burst. In section $5 \mathrm{a}$, we will demonstrate an example showing that during the wind burst, the lateral homogenization of the upper ocean is observed not only within the mixed layer but also in the deeper layers. The reasonable explanation of this fact is that the internal inertial-gravity waves account for most of the observed horizontal variability in the density and velocity fields. Relatively fast absorption of the internal wave energy within the whole water column during the westerly wind burst can then be ex- plained by the Phillips (1977) type interaction of the near-surface turbulence and internal wave field (see appendix A). Further analysis described in this and the next section therefore proceeds with the hypothesis that the observed fluctuations of velocity and density in horizontal direction are due to internal waves. Processes other than internal waves will be briefly discussed in section $5 \mathrm{c}$.

\section{a. Frequency and wavenumber spectra}

The wavenumber spectral analysis is an effective tool to describe the statistics of horizontal variability of the upper ocean. The velocity and density spectra are being calculated from the Wecoma surveys (using the ADCP and SEASOAR data); the algorithm is close to that used by Soloviev et al. (1988) for the analysis of short, nonstationary datasets. The subroutine includes the subtraction of mean and windowing the data in the time domain (we used the Hanning data window). The windowed data are brought to zero smoothly at the boundaries to minimize "leakage" in the spectral domain and, hence, to increase the dynamical range of the analysis (Rabiner and Gould 1975). For the "-2" power spectra, being analyzed in this paper, the spectral leakage is, however, relatively small. The spectra are being normalized as follows, $\int_{0}^{\infty} S(f) d f=\sigma^{2}$, where $S(f)$ is the 

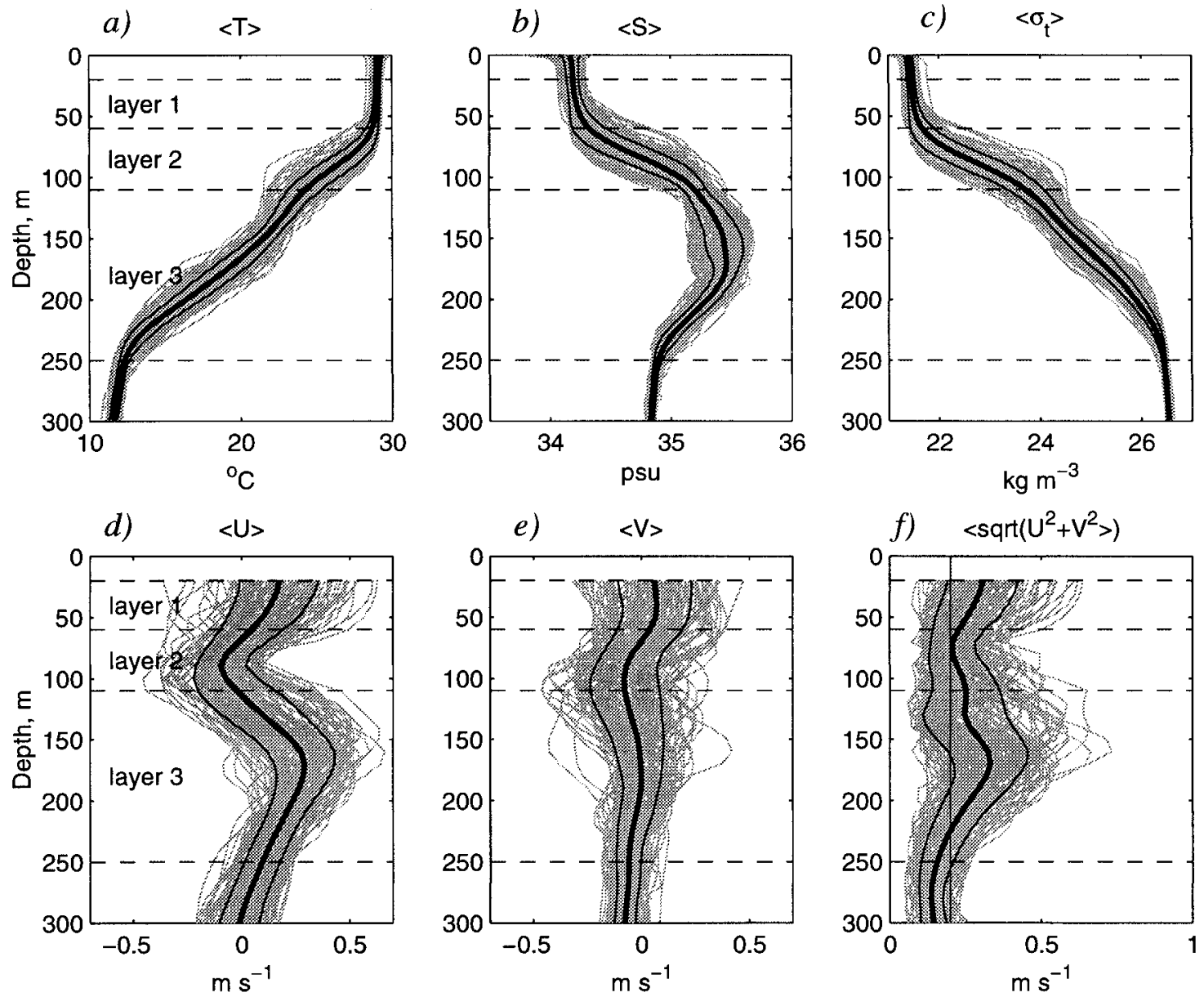

FIG. 3. Light lines are the ensembles of temperature $(\langle T\rangle)$, salinity $(\langle S\rangle)$, density $\left(\left\langle\sigma_{t}\right\rangle\right)$, zonal and meridional velocity $(\langle U\rangle$ and $\langle V\rangle)$, and horizontal velocity magnitude $\left(\left\langle\operatorname{sqr}\left(U^{2}+V^{2}\right)\right\rangle\right)$ profiles (angle brackets denote averaging over the individual Wecoma section). Bold lines are averages over all Wecoma individual sections. Thin lines correspond to one standard deviation. Straight vertical line on subplot $f$ is the velocity magnitude of $0.2 \mathrm{~m} \mathrm{~s}^{-1}$-the Garrett and Munk (1972) criteria for use of the frozen field approximation.
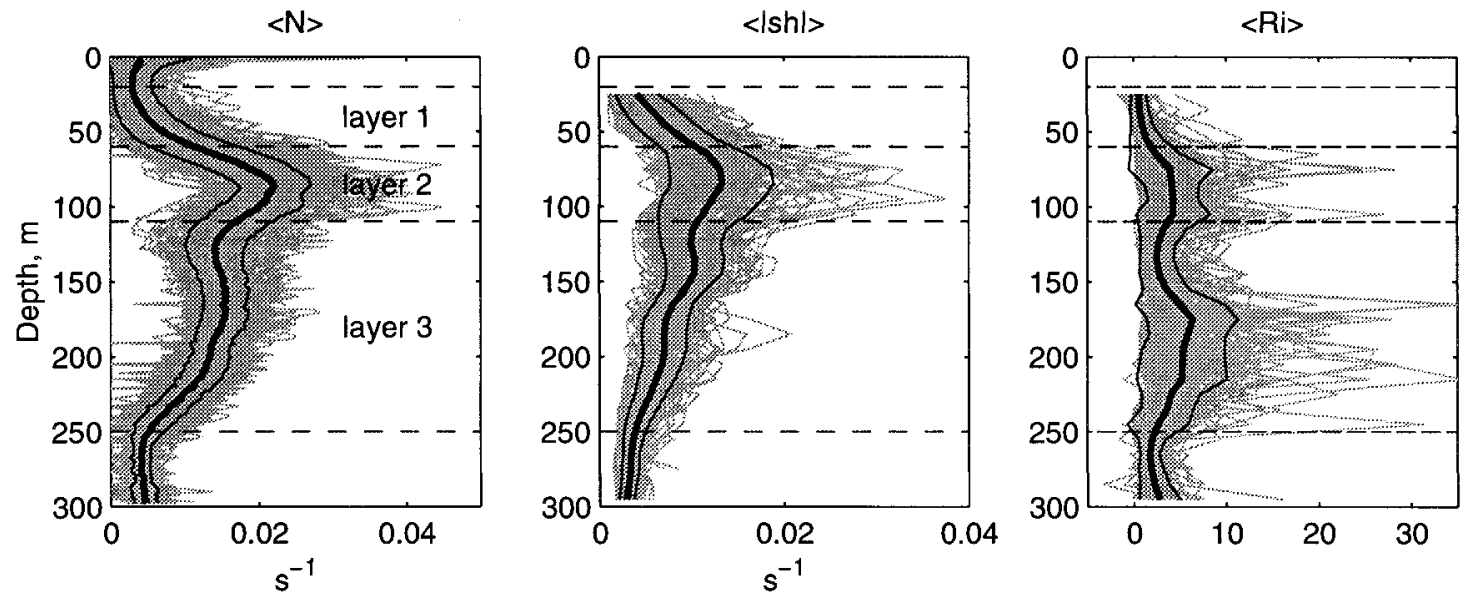

FIG. 4. Light lines are the ensembles of buoyancy frequency $\langle N\rangle$, magnitude of vertical shear $\langle|\operatorname{Sh}|\rangle$, and Richardson number $\langle\mathrm{Ri}\rangle$ profiles (angle brackets denote averaging over individual Wecoma section). Bold lines are averages over all Wecoma individual sections. Thin lines correspond to one standard deviation. 
frequency spectra, $f$ the frequency in hertz, and $\sigma^{2}$ the variance.

Because of the Doppler effect, instruments record the oscillations not with true but with observed (apparent) time frequency $f=f_{t}-U_{o} / \lambda$, where $f_{t}$ is the true oscillation frequency, $U_{o}$ is the difference in the velocity of the instrument and that of the water, and $\lambda$ is the apparent wavelength (in the direction of the velocity vector $\mathbf{U}_{o}$ ). The temporal changes recorded by instruments can be due to the temporal variability and/or advection past it of spatial inhomogeneties. The relative contributions of the temporal and spatial variability to the measured spectrum depends on ratio $r=U^{\prime} / U_{o}$, where $U^{\prime}=\lambda / \tau$ is the velocity scale and $\tau$ is the timescale for the evolution of the structures of dimension $\lambda$. Interpretation of the experimental spectra is most simple at extreme values of $r$. At $r \gg 1$ (a slow advection or towing), spectrum $S(f)$ is close to the true frequency spectrum of the measured process. Conversely, at $r \ll$ 1 (a fast towing), there is no significant change of the structures of dimension $\lambda$ during its passage through the instrument. In the latter case, the frequency spectrum can be transformed into the wavenumber domain, using the "frozen field" approximation:

$$
k=2 \pi f U_{o}^{-1}, \quad E(k)=(2 \pi)^{-1} S(f) U_{o},
$$

where $f$ is the frequency in $\mathrm{Hz}, U_{o}$ is the relative flow speed (towed or mean flow advection speed), and $k$ is the wavenumber in inverse meters $(k=2 \pi / \lambda)$. Formulas similar to (1) have been widely used in the turbulence analysis, based on the frozen field hypothesis of Taylor (1938). Taylor's hypothesis requires variability of the relative flow to be within $10 \%(r<0.1)$.

The pertinent velocity scale for the isotropic internal waves is the phase velocity of the equivalent single mode, $U^{\prime}=U_{r} \approx 0.2 \mathrm{~m} \mathrm{~s}^{-1}$ (Garrett and Munk 1972). The Wecoma data represents with good accuracy the spatial variability of the random internal wave field because $r \approx 0.05 \ll 1$. Application of the frozen field approximation in this case is fully justified.

The pertinent velocity scale for semidiurnal tidal internal waves (the phase velocity), $U^{\prime}=U_{t} \approx 2-3 \mathrm{~m}$ $\mathrm{s}^{-1}$ (Feng et al. 1998). The WHOI moored instruments measured the temporal variability of the semidiurnal tidal internal waves with minimal disturbances because $r \approx 10-15 \gg 1$. The Doppler effect for the tidal internal waves will be considered qualitatively in section $4 \mathrm{~d}$ and accounted explicitly in section 5 with the Feng et al. (1998) model.

\section{b. Finestructure contamination}

The signal from towed and moored sensors may contain high-frequency contamination because of the finestructure $[O(1 \mathrm{~m})$ vertical scales] in the vertical profiles (Munk 1981). The vertical finestructure contamination can be substantially reduced by vertically averaging the signal. The finestructure contamination of the velocity spectra is therefore much reduced for the ADCP measurements because the corresponding signals are averaged in the vertical direction [this is similar to the measurement of internal waves by "distributed" sensors (Konyaev 1990).]. For the SEASOAR data, additional depth averaging may not eliminate the finestructure contamination because of the undulation nature of profiles. The undulated profiles can also be contaminated with horizontal structures because of finescale intrusions (Huyer et al. 1997).

\section{c. Effect of mean flow shear advection (kinematic contamination of velocity spectra)}

According to the Wecoma surveys in the warm pool area, there are strong mean flow shears in the zonal direction between the Yoshida jet, the South Equatorial Current, and the Equatorial Undercurrent (Fig. 3d). The vertical advection of the mean flow shear by internal waves (Boyd et al. 1993; Chereskin et al. 1986; and others) results in the kinematic contamination of the measured velocity spectra. Density $\left(\rho^{\prime}\right)$ and horizontal velocity $\left(U^{\prime}\right)$ fluctuation due to vertical displacement of isopycnal in the internal wave $\zeta$ in linear approximation are estimated as follows:

$$
\rho^{\prime} \approx \zeta \partial \rho / \partial z, \quad U^{\prime} \approx \zeta \partial U / \partial z
$$

where $\partial U / \partial z$ and $\partial \rho / \partial z$ are the mean vertical shear and density gradient correspondingly. Note, that the second expression does not include orbital velocity of internal waves.

The kinematic contamination of the velocity spectrum can be estimated in the following way:

$$
E_{k}(k)=E_{\zeta}(k)(\partial U / \partial z)^{2},
$$

where $E_{\zeta}(k)$ is vertical displacement spectra and $\partial U / \partial z$ is the mean vertical shear. For internal waves with frequency $f \gg f_{0}$, the spectrum of horizontal velocity is related to the spectrum of vertical displacement in the following way:

$$
E(k)=E_{\zeta}(k) N^{2},
$$

where $N$ is the Brunt-Väisälä frequency and $f_{0}$ is the inertial frequency.

According to (2), the density and kinematic velocity fluctuations are in the same or opposite phase, depending on the sign of mean density and velocity gradients. The fluctuation of density produced by linear internal waves is always shifted in phase by $\pm 90^{\circ}$ compared to the fluctuation of orbital velocity (otherwise, the linear internal wave would transport mass). The phase difference between the kinematic contamination and the orbital velocity is therefore $\pm 90^{\circ}$, so the cross-spectrum between the kinematic contamination and orbital velocities is equal to zero. The measured velocity spectrum is therefore the simple sum of (3) and (4):

$$
E_{m}(k)=E_{k}(k)+E(k)=E(k)\left[1+(\partial U / \partial z)^{2} / N^{2}\right] .
$$


According to (5), the measured velocity spectrum can be corrected for the kinematic contamination in the following way:

$$
E(k)=E_{m}(k) /\left(1+\mathrm{Ri}^{-1}\right),
$$

where $\mathrm{Ri}=N^{2} /(\partial U / \partial z)^{2}$ is the gradient Richardson number. According to (6), the kinematic contamination may be substantial in the surface mixed layer where the Richardson number is relatively small (Fig. 4). Note that (6) can also be obtained as an asymptote $(\omega \ll N)$ of a relation for the kinetic-to-potential energy ratio derived by Boyd et al. (1993) with the WKB approximation.

\section{d. Tidal waves and Doppler effect}

Based on the mooring observations, Picaut et al. (1995) and Pinkel et al. (1997) reported an energetic semidiurnal tide observed during the COARE IOP. Analysis of the IFA mooring data indicates that the semidiurnal tide consists of comparable baroclinic and barotropic current amplitudes in the upper ocean and that a significant portion of the baroclinic tide is coherent with the barotropic tide with a dominant northeast-southwest current orientation. Feng et al. (1998) estimated the baroclinic and barotropic tidal amplitudes and phases from survey and mooring observations in IFA. The barotropic tide is assumed to have zero horizontal wavenumber, while a component of the baroclinic tide was determined by a searching method using plane wave fits to both the isopycnical and velocity data. The plane wave analysis done for the baroclinic tidal component is consistent with a dominant mode one baroclinic wave propagating toward the northeast.

The energetics of the tide are such that high-frequency undular bores are observed to be associated with the baroclinic tidal waves (Pinkel et al. 1997). The Feng et al. (1998) model works during the nonlinear tidal periods as well, but it assesses only the dominant (linear) mode of the semidiurnal tide, which typically accounts for $40 \%-60 \%$ of the observed semidiurnal band current variance in the mooring data.

Qualitative consideration of the Doppler effect in application to the R/V Wecoma surveys suggests that the influence of internal tides should be maximum for the north-south sections. For the west-east sections, the ship direction is such that the apparent wavelength of tide increases and exceeds the section length. For the south-west and north-east sections, the ship moves almost parallel to the front of $M_{2}$ and $S_{2}$ baroclinic tides, thus increasing the apparent tidal wavelength and diminishing its influence on the measurements. The quantitative estimates of the Doppler shifted tidal waves will be done in the next section, using the model of Feng et al. (1998).

\section{Discussion}

a. Comparison of field data with internal wave spectral model

Figure 5a-c shows the east- $(U)$ and north- $(V)$ component velocity spectra for three Wecoma sections corresponding to the conditions of moderate wind speed (24 December 1992), a strong westerly wind burst (1 January 1993), and low wind speed (4 January 1993). The spectra are averaged over the following three depth ranges: 1) 20-60 m, 2) 60-110 m, and 3) 110-250 m, approximately corresponding to the Yoshida jet, the South Equatorial Current, and the southern edge of Equatorial Undercurrent (Lukas et al. 1995). In this example, linear trends are subtracted from the data before the spectral calculations. In Fig. 5, depth ranges 1, 2, and 3 are represented by continuous, dashed, and dotdashed lines correspondingly.

The horizontal fluctuations of density and velocity decreased on 1 January 1993, under conditions of strong westerly wind burst (Fig. 5). The reduction of spectral energy of the density and velocity fluctuations is observed not only in layer 1, directly interacting with the atmosphere, but also in the deeper layers $(2$ and 3). This unusually rapid change of spectral levels during a westerly wind burst, happening far below the mixed layer, is consistent with the hypothesis that most of the observed horizontal variability of density and velocity fields is caused by internal waves. The Phillips (1977) type interaction of near-surface turbulence and internal wave field can result in a relatively fast absorption of the internal wave energy within the whole water column during the westerly wind burst (see appendix A).

In Fig. 5, we also compare the wavenumber density and velocity spectra with an internal wave model. An equatorial version of Garrett and Munk spectrum (appendix B) is given in Figs. 5d-f. The spectra of vertical displacement, shown in Fig. 5d, are calculated using the following relationship:

$$
E_{\zeta}(k)=E_{\rho}(k)(\overline{d \rho / d z})^{-2} \approx E_{\rho}(k) g^{2}\left(\overline{N^{2}}\right)^{-2} \rho^{-2} .
$$

The measured velocity spectra are corrected for the kinematic contamination using (6). The corrected velocity spectra are shown in Fig. 5e. Figure 5f summarizes the velocity and vertical displacement spectra in normalized coordinates. Being normalized according to the internal wave scaling, the density and velocity spectra coincide well with each other. This is further evidence that the internal waves might be a major contributor to the horizontal variability of density and velocity fields on scales from 6 to $120 \mathrm{~km}$ in the warm pool area.

The ensembles of scaled density and velocity spectra for all Wecoma sections in the three depth ranges, 20$60 \mathrm{~m}, 60-110 \mathrm{~m}$, and 110-250 m, are calculated from detrended datasets, using the time averaged density and velocity fields. Single one-point gaps are linearly interpolated. Horizontal records containing the gaps of 
more than one point, significant changes of ship speed, and/or course are eliminated from the spectral analysis. The spectra from individual sections are then averaged over the three depth ranges and smoothed in wavenumber domain using the windows $k / \Delta k=3.4$ for density and $k / \Delta k=3.2$ for velocity, where $k$ is the wavenumber and $\Delta k$ is the window width. Before averaging and smoothing, the spectra are prewhitened by multiplying them by $k^{2}$ because the observed spectra are close to " -2 " power dependence. The prewhitening improves the statistical reliability of spectral estimates by reducing the leakage from the most intense spectral components and low-frequency components that are poorly resolved (Emery and Thompson 1998). After averaging in the wavenumber domain, the spectra are multiplied by $k^{-2}$, respectively. The velocity spectra are additionally corrected for the effect of mean flow shear advection (kinematic contamination) using (6).

The spectra averaged over all sections and three depth ranges are plotted in Fig. 6 together with the 95\% equaltail confidence intervals (Oppenheim and Schaffer 1975). In Fig. 6, the Wecoma spectra are compared with the Garrett and Munk model of isotropic internal waves and with the Feng et al. (1998) model of semidiurnal internal waves. The tidal model is applied in such a way that it takes into account the Doppler effect. According to Fig. 7, the model tidal spectra are far below the density and velocity spectra obtained from the R/V Wecoma surveys. According to estimation shown in Table 1, only spectra from the north-south Wecoma sections are appreciably influenced by internal tides (this is consistent with the results of qualitative consideration of the Doppler effect in section 4d). Note that the values in Table 1 are spectra averaged over all three Wecoma cruisesfor the individual Wecoma sections, the tidal correction is sometimes more pronounced.

In Fig. 7, the tidal model of Feng et al. (1998) is tested with the WHOI mooring velocity data. After subtracting the model tidal signal from the WHOI mooring dataset, the tidal peak is no longer prominent on the spectra (at a 95\% confidence interval). In the warm pool area, the moored spectra (Fig. 7) are much stronger influenced by the tidal internal waves than the towed ones (Fig. 6); the tidal component is pronounced in the frequency but not in the wavenumber domain.

Figure 8 summarizes the averaged velocity and den- sity spectra for each of three depth ranges. The spectra are compared with the Garrett-Munk model. Different authors have used slightly different versions of the Garrett and Munk spectrum. Figures 7 and 8 demonstrate two versions of the Garrett and Munk spectrum. GM79a is the Garrett-Munk spectrum calculated for 30 modes and then divided by 3 (Eriksen et al. 1988), GM79b is the Garrett-Munk spectrum for 20 modes with the first mode multiplied by 0.3 (Boyd et al. 1993). The scaled velocity and density spectra are consistent with each other and are close to the Garrett and Munk theoretical model. In layer 2, the scaled spectra of density are somewhat higher than those of velocity; this difference is confidently resolved in the experimental spectra because of substantial statistics acquired during the R/V Wecoma surveys.

Note that the sparse cases with strongest fronts (listed in section 5c) as well as with $\mathrm{Ri}<\mathrm{Ri}_{c}=0.3$ are not included into the spectral averages shown in Figs. 6 and 8 . This results in a slightly better agreement between the scaled density and velocity spectra in layer 1 but practically does not change the averaged spectra in layers 2 and 3.

Figure 9 shows the scaled COARE spectra from the $\mathrm{R} / \mathrm{V}$ Wecoma and from the WHOI mooring in comparison with the historical towed spectra from Garrett and Munk (1972). The Wecoma spectra are well consistent with the historical towed spectra.

\section{b. Directional anisotropy of the velocity field variability}

For isotropic models of internal waves, in the limit $\omega^{2} \ll N^{2}$, the WKB expression for $\left\langle u^{2}\right\rangle /\left\langle v^{2}\right\rangle$ is as follows:

$$
\left\langle u^{2}\right\rangle /\left\langle v^{2}\right\rangle=\left(1+2 \mathrm{Ri}_{u}^{-1}\right) /\left(1+2 \mathrm{Ri}_{v}^{-1}\right),
$$

where $\mathrm{Ri}_{u}=N^{2} / U_{z}^{2}$ and $\mathrm{Ri}_{v}=N^{2} / V_{z}^{2}$ (Boyd et al. 1993). Table 2 compares the observational and theoretical values of the zonal to meridional kinetic energy ratio. Within the depth range from 60 to $250 \mathrm{~m}$, both theory and measurements show that the velocity field is almost spatially isotropic. There is, however, some directional anisotropy of the velocity field in the upper layer (20-60 $\mathrm{m})$. The fluctuation energy of zonal velocity is larger than that of the meridional velocity. The difference be-

TABLE 1. Tidal correction in percent calculated as $[\operatorname{sum}(E(k))-\operatorname{sum}(E d t(k))] / \operatorname{sum}(E d t(k))$, where $E(k)$ and $E d t(k)$ are the spectra before and after tidal correction correspondingly. Summation is over the wavenumber range corresponding to the wavelengths from 30 to $120 \mathrm{~km}$ for long sections (WE and NS) and from 20 to $90 \mathrm{~km}$ for shorter sections (SW and EN). ADCP is the left and SEASOAR is the right column. Statistically prominent values of the tidal correction are in boldface type.

\begin{tabular}{|c|c|c|c|c|c|c|c|c|}
\hline \multirow[b]{3}{*}{ Depth range (m) } & \multicolumn{8}{|c|}{ Wecoma section } \\
\hline & \multicolumn{2}{|c|}{ W2E } & \multicolumn{2}{|c|}{$\mathrm{N} 2 \mathrm{~S}$} & \multicolumn{2}{|c|}{ S2W } & \multicolumn{2}{|c|}{ E2N } \\
\hline & $\mathrm{ADCP}$ & SEASOAR & $\mathrm{ADCP}$ & SEASOAR & $\mathrm{ADCP}$ & SEASOAR & $\mathrm{ADCP}$ & SEASOAR \\
\hline $20-60$ & 3 & 2 & 24 & 6 & 7 & -8 & 5 & 4 \\
\hline $60-110$ & 3 & 7 & 22 & 19 & 6 & 5 & 9 & 1 \\
\hline $110-250$ & 8 & 5 & 23 & 30 & 1 & 11 & 3 & 6 \\
\hline
\end{tabular}


West-to-east section, 24 December 1992
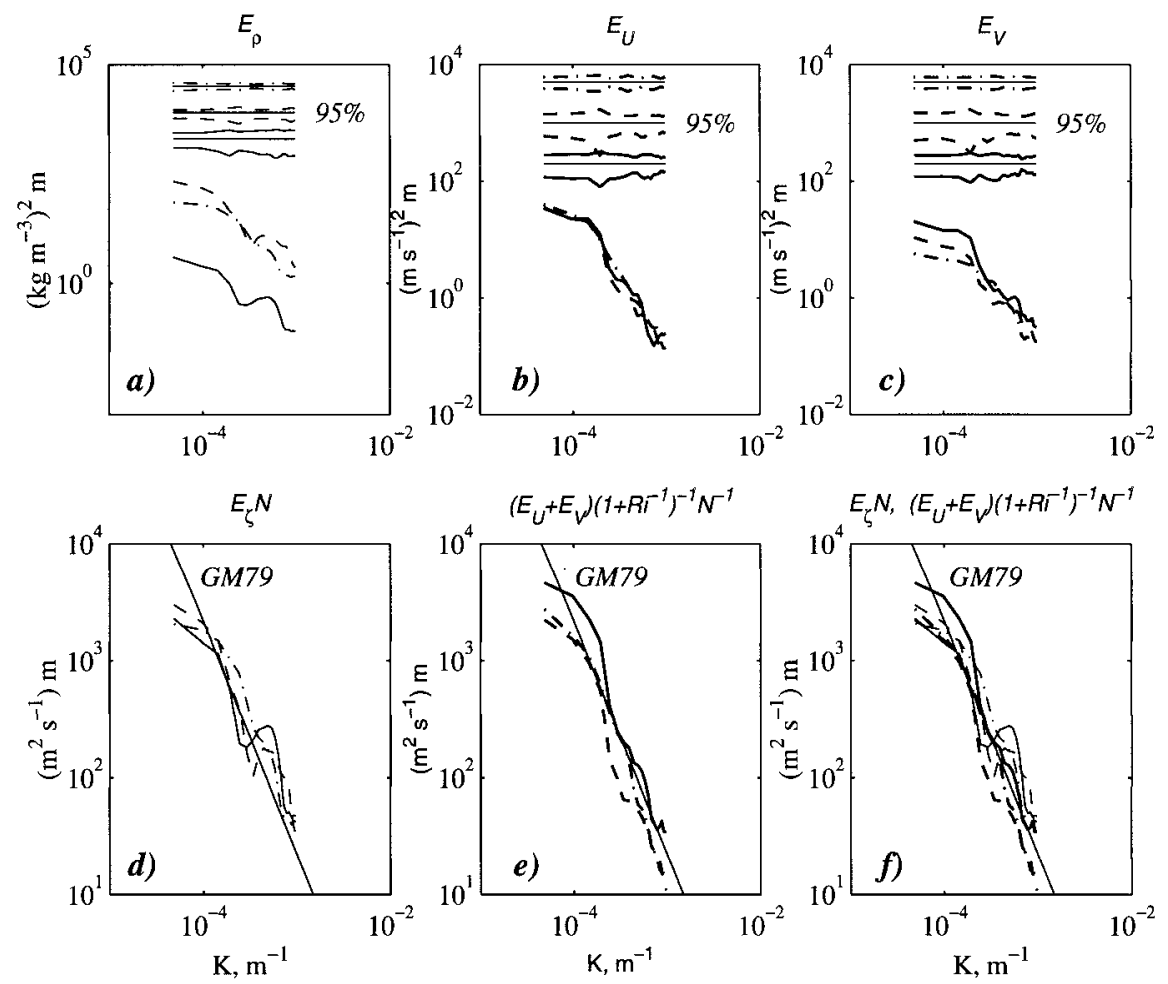

FIG. 5. (a)-(c) Examples of density $\left(E_{\rho}\right)$, and velocity $\left(E_{u}, E_{v}\right)$ wavenumber spectra from the Wecoma west-to-east sections, 24 December 1992, and of their WKB-scaling. (d)-(f) Density displacement spectra $\left(E_{\xi}\right)$ are calculated using (7). Continuous, dashed, and point-dashed lines correspond to the depth ranges 20-60,60-110, and 110-250 m. The 95\% (equal tails) error bars are shown by the corresponding types of lines. GM79 is an "equatorial" version of Garrett and Munk spectrum (see appendix B).

tween the observation and theory is within the scatter of the data.

\section{c. Sources of horizontal variability other than internal waves}

According to analysis described in this and previous chapters, on scales 6-120 km the internal inertial-gravity and tidal waves can account for most of the horizontal density and velocity variability in the warm pool area within the depth range from 20 to $250 \mathrm{~m}$. Apparently, processes other than internal waves can also contribute to the horizontal variability, especially within the depth range from 0 to $20 \mathrm{~m}$, because the near-surface turbulence absorbs the internal waves. Alternative processes may include fronts and intrusions, submesoscale eddies, and response to atmospheric forcing with meso and small spatial scales (diurnal warming, precipitation, wind bursts, etc.).

Intrusions and fronts are the typical features of the horizontal density and velocity fields in the warm pool area. The intrusions with horizontal scales up to 120 $\mathrm{km}$ were observed by Huyer et al. (1997) in the warm pool area in the thermocline region and also in the undercurrent core. The computed towed spectra may therefore be contaminated with finescale intrusions. This is

TABLE 2. Ratios of average zonal to meridional spectral kinetic energy $\operatorname{sum}\left(E_{u}(k)\right) / \operatorname{sum}\left(E_{v}(k)\right)($ Wecoma COARE IOP legs 1,2 , and 3).

\begin{tabular}{|c|c|c|c|c|c|c|c|c|c|c|}
\hline \multirow[b]{3}{*}{ Depth range $(\mathrm{m})$} & \multicolumn{8}{|c|}{ Wecoma section } & & \\
\hline & \multicolumn{2}{|c|}{ W2E } & \multicolumn{2}{|c|}{$\mathrm{N} 2 \mathrm{~S}$} & \multicolumn{2}{|c|}{ S2W } & \multicolumn{2}{|c|}{$\mathrm{E} 2 \mathrm{~N}$} & \multicolumn{2}{|c|}{ Average over all sections } \\
\hline & Obs & Theory & Obs & Theory & Obs & Theory & Obs & Theory & Obs & Theory \\
\hline $20-60$ & 1.19 & 1.31 & 0.89 & 1.28 & 1.36 & 1.17 & 1.04 & 1.35 & 1.12 & 1.28 \\
\hline $60-110$ & 1.08 & 1.04 & 0.88 & 1.05 & 1.14 & 0.98 & 1.01 & 1.00 & 1.03 & 1.02 \\
\hline $110-250$ & 1.08 & 1.01 & 1.12 & 1.03 & 0.85 & 1.02 & 1.08 & 1.02 & 1.03 & 1.02 \\
\hline
\end{tabular}


West-to-east section, 1 January 1993
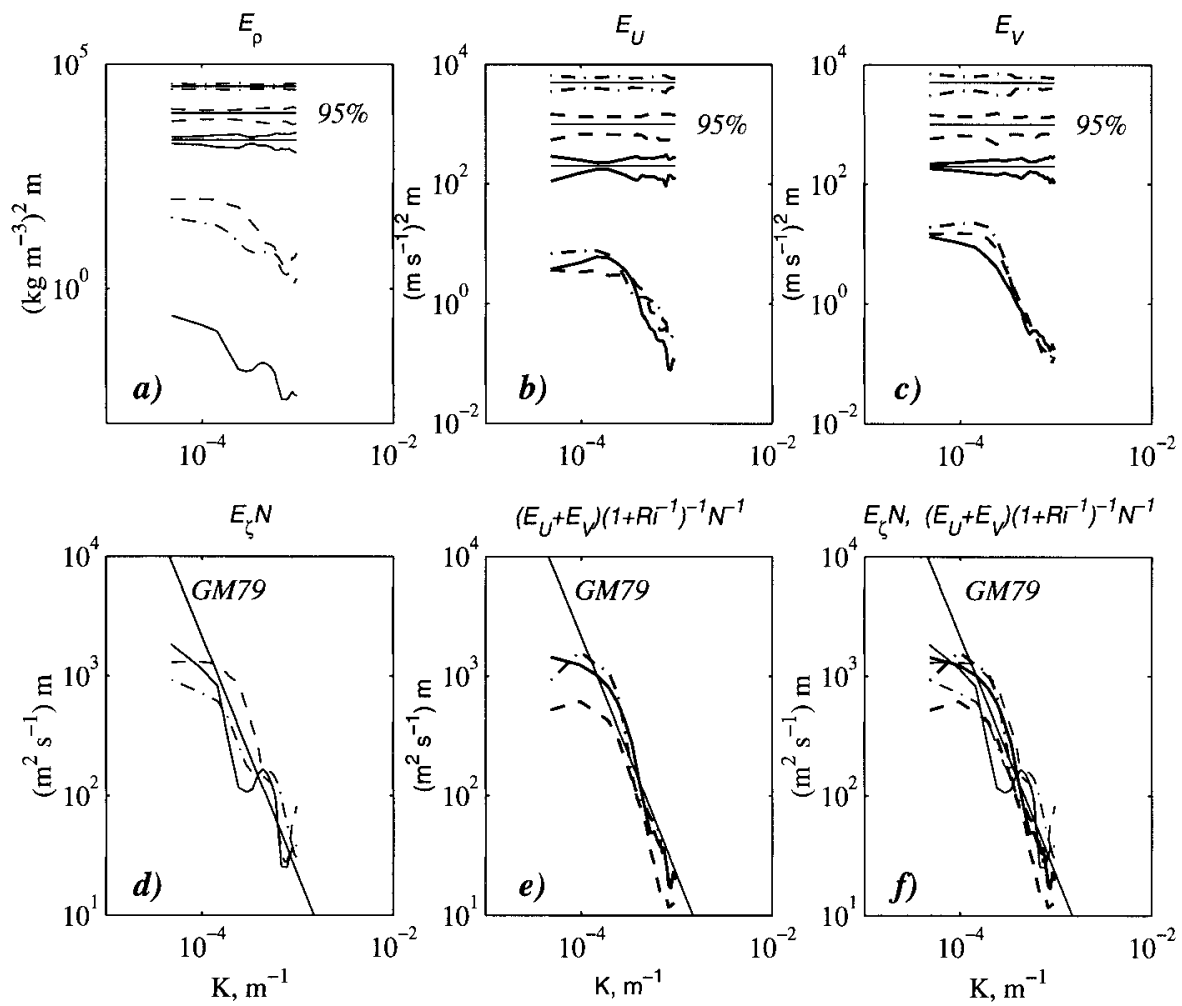

West-to-east section, 4 January 1993
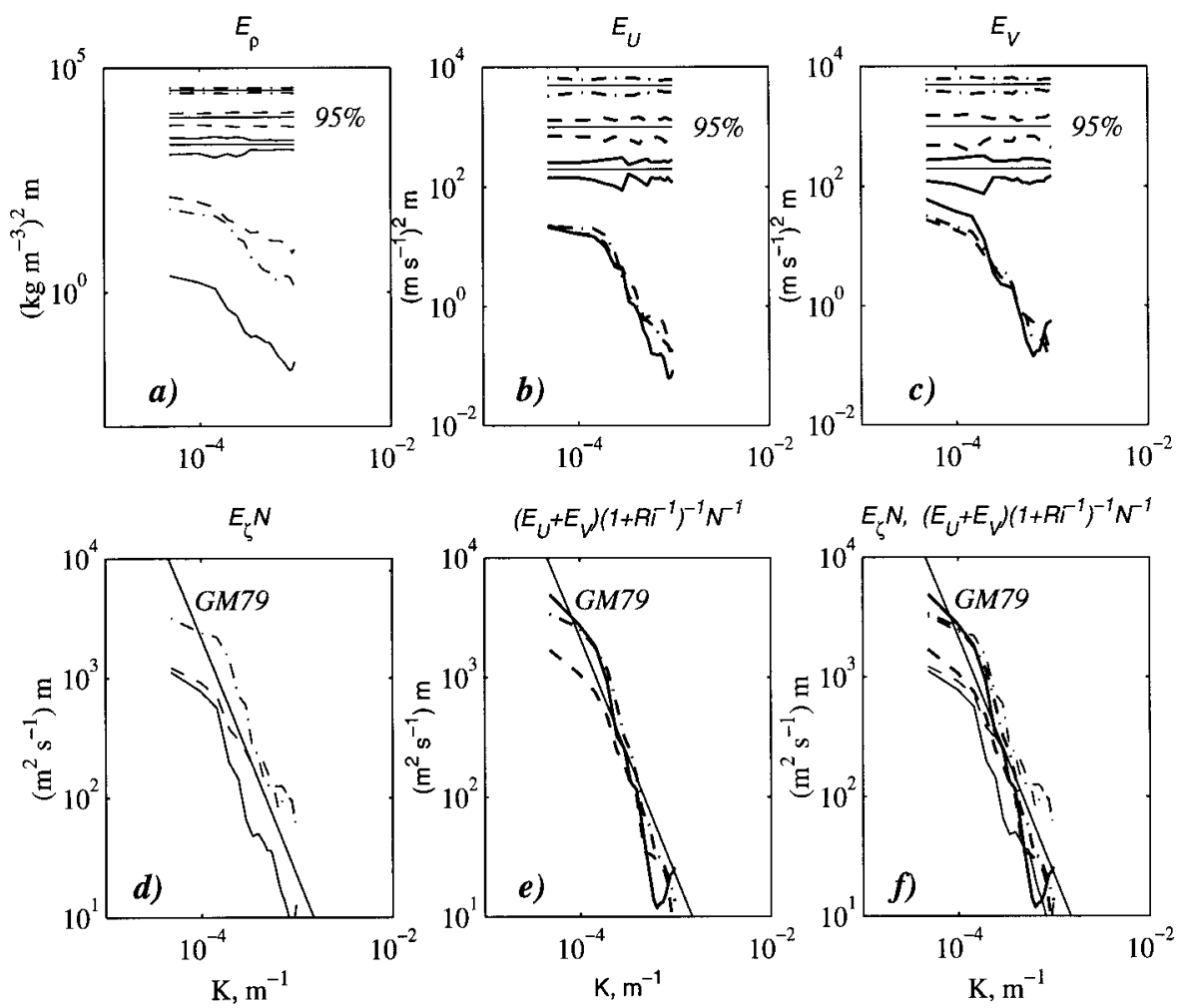

FIG. 5. (continued) 

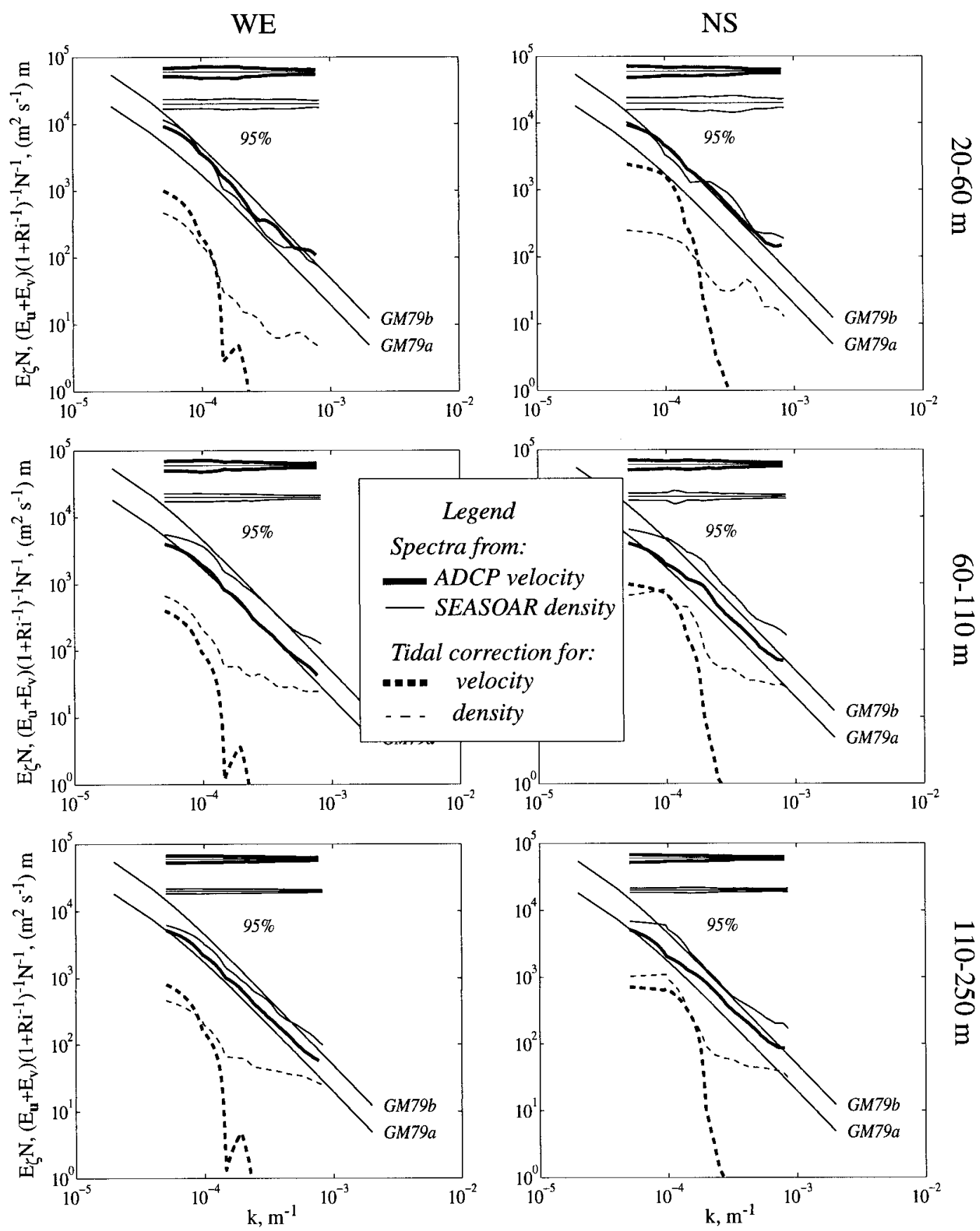

FIG. 6. Averaged density and velocity wavenumber spectra for all Wecoma surveys and tidal correction from model of Feng et al. (1998). The spectra are normalized according to internal wave scaling and point-dashed lines correspond

a possible reason why in layer 2 , the scaled spectra of density are systematically higher than those of velocity (Fig. 8).

During COARE IOP, a front was observed between high-salinity southern and low-salinity northern waters (Huyer et al. 1997). This front was often narrow ( $~ 30$ $\mathrm{km})$. It migrated meridionally between and within the
$\mathrm{R} / \mathrm{V}$ Wecoma IOP cruises at a speed consistent with advection by the Equatorial Undercurrent. Secondary salinity inversions with lateral scales of $10-50 \mathrm{~km}$ were observed above and below the high-salinity core. Although the frontal features can generate a " $k^{-2}$ " spectrum (i.e., of the same shape as the spectrum of random internal wave field), it is quite unlikely that the WKB 

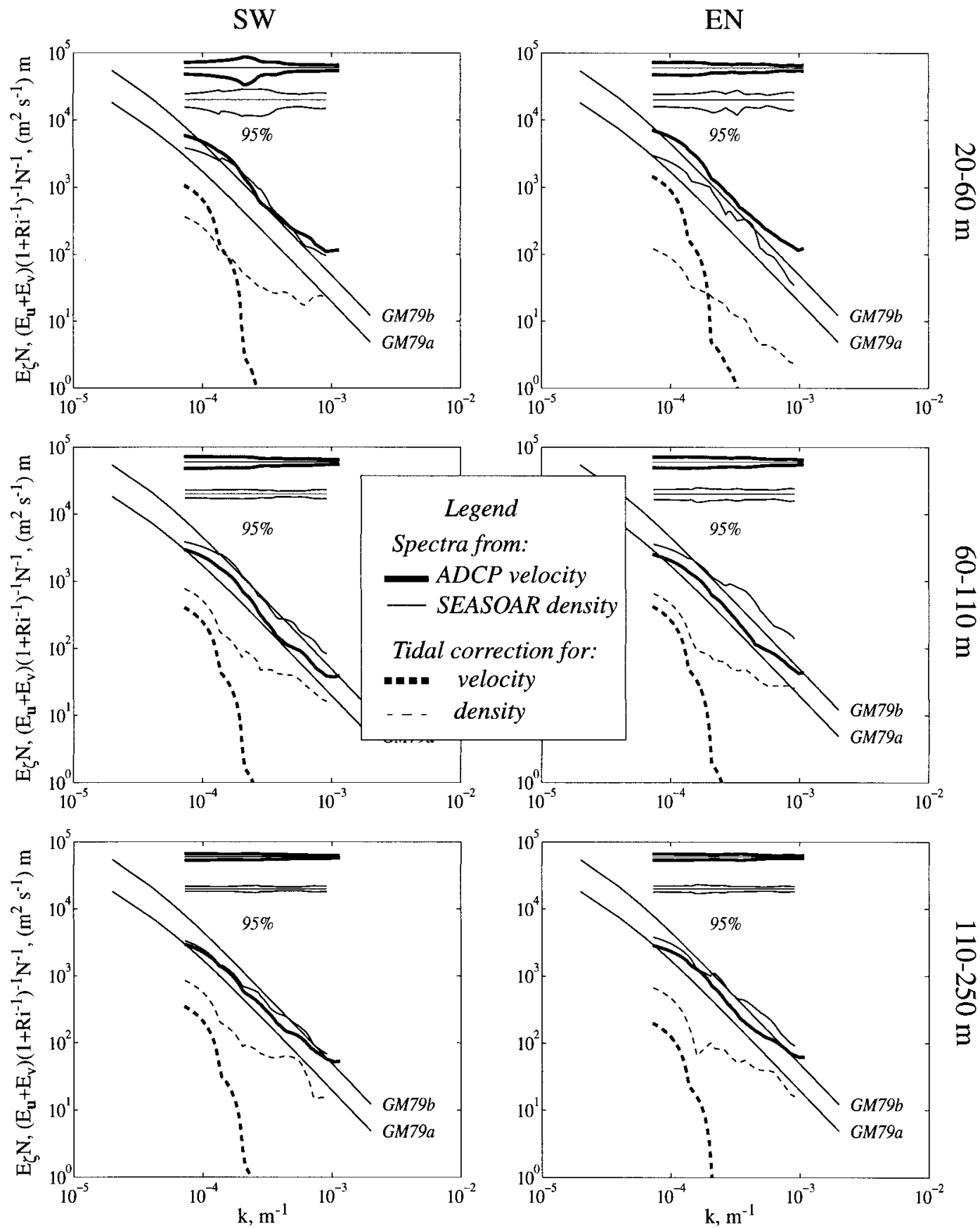

FIG. 6. (Continued) to the depth ranges 20-60, 60-110, and 110-250 m. The 95\% (equal tails) error bars are shown by the corresponding types of lines. GM79a is the Eriksen et al. (1988) and GM79b is the Boyd et al. (1993) version of the Garrett-Munk spectrum.

scaled density and velocity spectra of frontal features coincide with each other and, moreover, with the Garrett and Munk spectrum.

Antonia et al. (1979), Soloviev (1990), and Thorpe et al. (1985) used the skewness of temperature derivative as a criteria for the presence of frontlike features in the atmospheric and oceanic turbulent boundary layers. To identify intersections of fronts during the Wecoma COARE surveys, we calculated the skewness of density derivative,

$$
\mu_{3}=\left\langle\left(\partial \sigma_{t} / \partial l-\left\langle\partial \sigma_{t} / \partial l\right\rangle\right)^{3}\right\rangle /\left\langle\left(\partial \sigma_{t} / \partial l-\left\langle\partial \sigma_{t} / \partial l\right\rangle\right)^{2}\right\rangle^{3 / 2}
$$




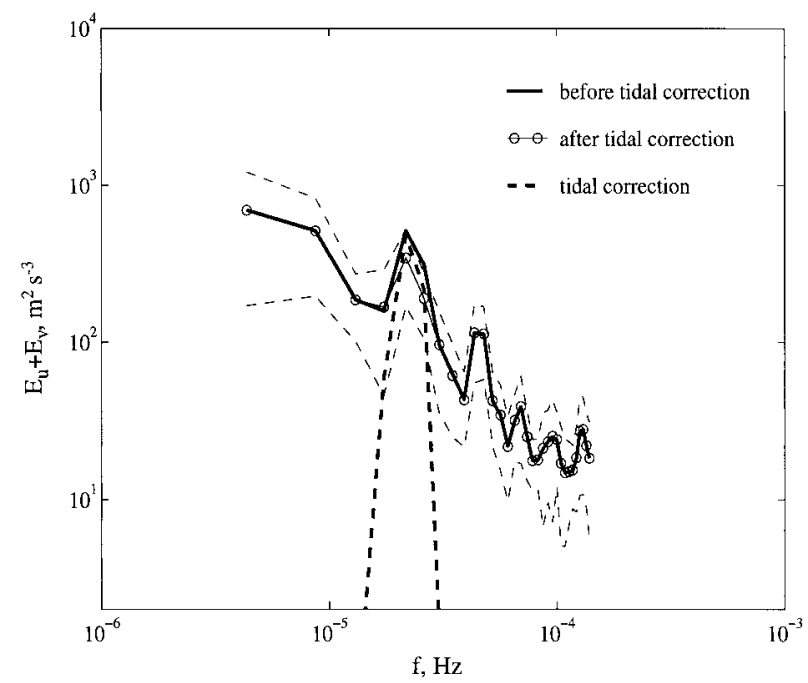

FIG. 7. Velocity spectra for WHOI mooring data at $52.5 \mathrm{~m}$ (Julian days 319.6-335.7) before and after tidal correction (calculated from 1-h averages). Thin dashed lines represent a $95 \%$ confidence interval for detide spectra.

(where $l$ is the horizontal coordinate and angle brackets denote averaging over the section) and averaged it within each of three layers. Sharp fronts $\left(\mu_{3} \geq 1\right)$ are detected in layer 1 (west-to-east sections on 6,7 , and 9 January 1993; north-to-south section on 15 November 1992 and 22, 24, 25, 28, and 29 December 1992 and 14 February 1993; south-to-west sections on 30 November 1992; east-to-north on 6 January 1993) and in layer 2 (west-to-east sections on 30 December 1992; north-south section on 24 December 1992; south-towest section on 11 February 1993; east-to-north section on 27 December), in layer 3 (north-to-south sections on 7 and 12 February 1993). The inclusion of cases with $\mu_{3} \geq 1$, however, results only in minor changes in the averaged spectra shown in Fig. 6, which is an indication that the contribution of the strongest fronts into the wavenumber statistics is not substantial.

During COARE IOP, Lukas et al. (1995) observed a strong density perturbation associated with a cyclonic submesoscale eddy with radius $\sim 40 \mathrm{~km}$ following a westerly wind burst. A Yoshida jetlike eastward surface current was spun up in the upper $70 \mathrm{~m}$ by a strong westerly wind burst that occurred from mid to late December 1992. When the winds became calm on 4 January 1993, the eastward jet began to rapidly spin down, and by 10 January it had disappeared. Part of the spindown process was the generation of an energetic, surface-intensified, cyclonic submesoscale eddy along the southern flank of the jet. Isopycnals in the eddy center came up from nearly $80 \mathrm{~m}$ almost to the surface. This eddylike feature was accompanied by a strong front detected during the west-to-east sections of the R/V Wecoma on 6, 7, and 9 January 1998. The relative frequency and spatial distribution of such ed- dies has not yet been determined. However, they are likely to be important only in conjunction with the westerly wind bursts and, therefore, does not seem to be the dominating process in forming the horizontal wavenumber spectra.

Response to atmospheric forcing with meso- and small temporal and/or spatial scales (processes such as diurnal warming, precipitation, squalls, westerly wind bursts) is another source of horizontal variability in the near-surface layer of the ocean in the warm pool area (Anderson et al. 1996; Brainerd and Gregg 1997; Lukas 1990; Smyth et al. 1996a,b; Soloviev and Lukas 1997; Wijesekera and Gregg 1996; Wijesekera et al. 1999). The horizontal inhomogeneouty in the heat, mass, and momentum flux may generate near-surface fronts, buoyancy driven currents, submesoscale eddies, and internal waves. The horizontal variability of the temperature and salinity in the warm pool area in the layer from 0 to 20 $\mathrm{m}$ has been analyzed in Wijesekera et al. (1999). The influence of the direct atmospheric forcing reduces with depth and vanishes below a 60-m depth, in particular, because of the presence of the "barrier layer" (Lukas and Lindstrom 1991; Huyer et al. 1997). To estimate the impact of the direct atmospheric forcing on the horizontal wavenumber spectra within the depth range from 20 to $60 \mathrm{~m}$, we included the spectra obtained at $\mathrm{Ri}<$ 0.3 (which were eliminated at calculation of the averaged spectra shown in Fig. 6) into the ensemble averaging. This merely changes the averaged spectral levels at low wavenumbers in layer 1 but practically does not influence the spectra averaged over layers 2 and 3-the cases with $\mathrm{Ri}<0.3$ are relatively sparse in the Wecoma dataset (even for layer 1).

\section{Conclusions}

Wavenumber velocity and density spectra are calculated from the R/V Wecoma surveys and averaged over three depth intervals: $20-60 \mathrm{~m}, 60-110 \mathrm{~m}$, and $110-250$ $\mathrm{m}$. The velocity spectra are corrected for the kinematic shear contamination (this correction is important for low Richardson number conditions). Both velocity and density wavenumber spectra from the Wecoma surveys are normalized using the internal wave scaling. In this scaling, the density and velocity spectra provide evidence in favor of the hypothesis that internal waves are the dominant process in forming the horizontal variability of velocity and density fields in the warm poll area on mesocales. The equatorial version of the Garrett and Munk model can account for much of the statistics of horizontal density and velocity variability in the warm pool area on scales $6-120 \mathrm{~km}$. For the mooring data, the model tidal spectra (Feng et al. 1998) coincide well the tidal peak on velocity spectra. For measurements from the moving ship, the tidal waves appear to be much smaller than the isotropic internal waves.

Acknowledgments. The authors gratefully acknowl- 
W-E, N-S, S-W, and E-N sections, depth range 20-60 m

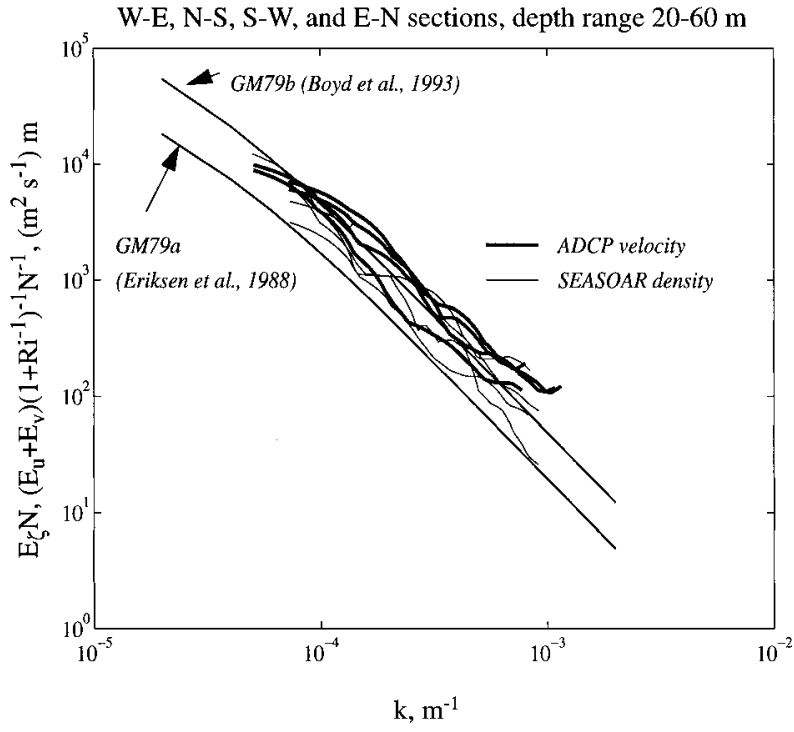

W-E, N-S, S-W, and E-N sections, depth range $110-250 \mathrm{~m}$

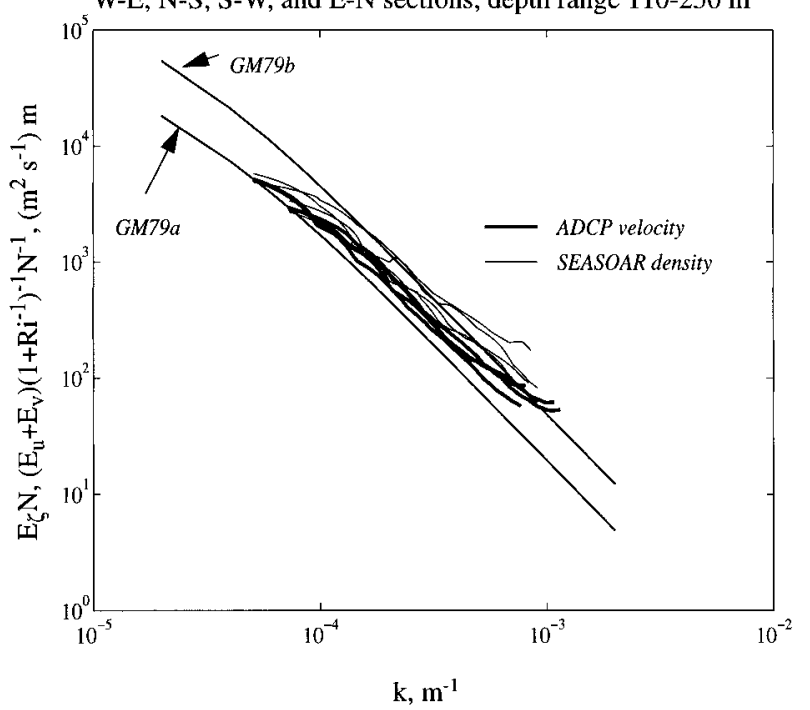

edge the TOGA COARE coinvestigators Eric Firing (University of Hawaii), A. Huyer, C. Paulson, and M. Kosro (Oregon State University), and R. Weller, A. Plueddemann, and S. Anderson (WHOI) for use of the datasets obtained during the TOGA COARE IOP. We thank Sharon DeCarlo and Patrick Caldwell (University of Hawaii) for help in access to the COARE database. We are grateful to Ming Feng (University of Hawaii) who helped us to incorporate the tidal correction model into the spectral analysis and to test it on the WHOI mooring data. We thank the anonymous reviewers for constructive comments. This work has been supported by NSF Grants OCE-911349 and OCE-9113948.

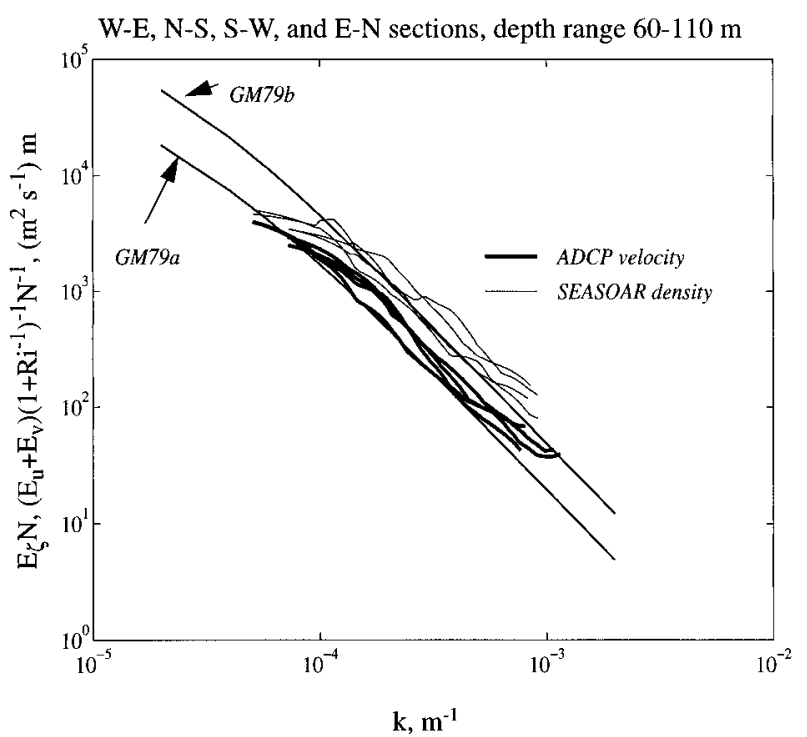

FIG. 8. Averaged horizontal density and velocity wavenumber spectra for three different depth ranges normalized according to internal wave scaling in comparison with the Garrett and Munk spectrum. GM79a is the Eriksen et al. (1988) and GM79b the Boyd et al. (1993) version of the Garrett-Munk spectrum.

\section{APPENDIX A}

\section{Mechanism of Strong Interaction of Internal Waves and Turbulence}

Phillips (1977, cited from Barenblatt 1978) reported observations of strong interaction of near-surface turbulence and internal waves in laboratory experiments. According to Barenblatt (1978) and Benilov (1973), the presence of turbulence results in the turbulent flux $\mathbf{J}$ of the wave energy $E_{\varphi}$ directed against its gradient:

$$
\mathbf{J}=-K_{\varphi} \operatorname{grad}\left(E_{\varphi}\right),
$$

where $K_{\varphi}$ is the coefficient of the wave energy turbulent 


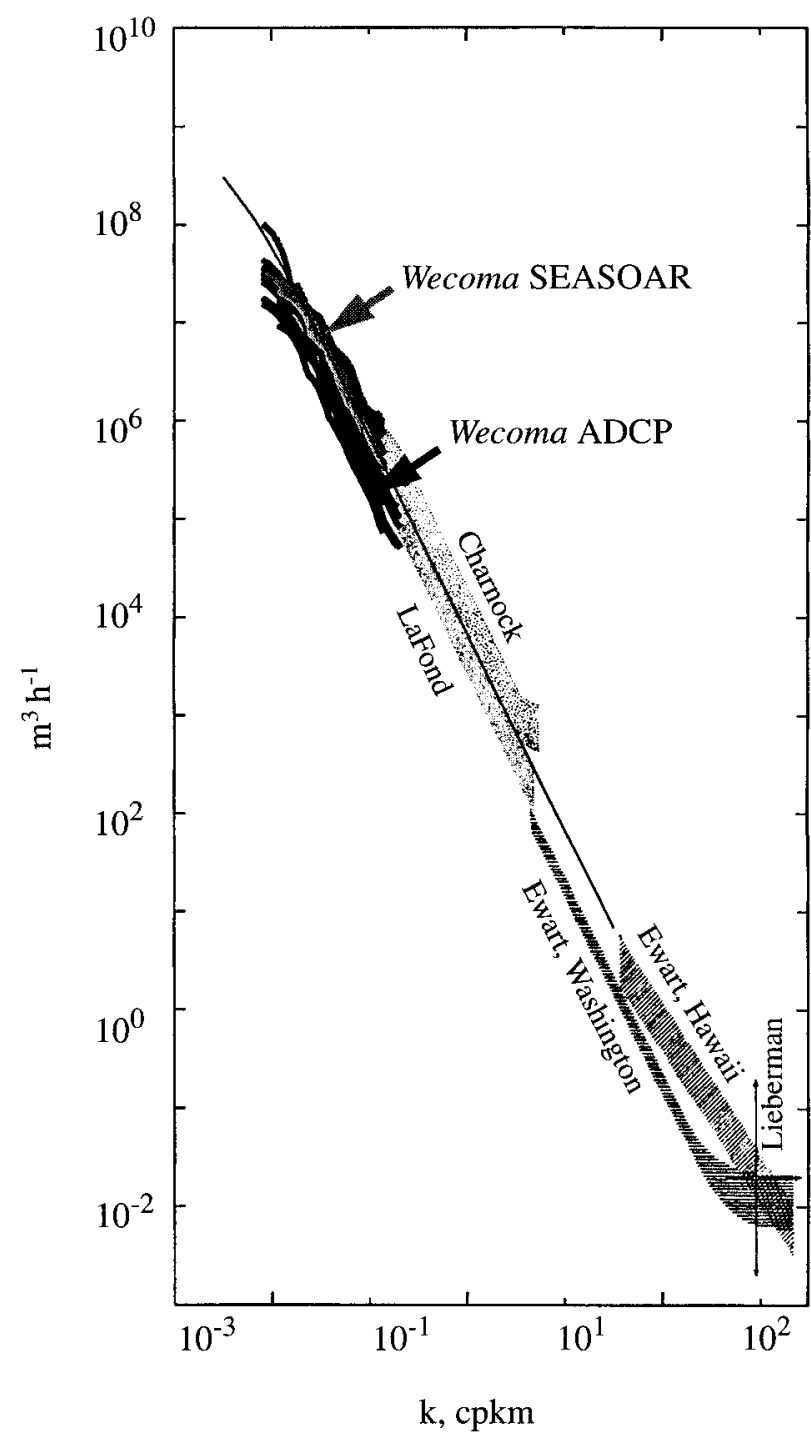

FIG. 9. Scaled density and velocity spectra from the TOGA COARE Wecoma surveys in a comparison with historical towed spectra from Garrett and Munk (1972).

exchange, which is introduced in the same way as the exchange coefficients for mass and momentum. Assuming that the Kolmogorov closure hypothesis is valid for the wave energy turbulent exchange, $K_{\varphi} \sim l b^{1 / 2} \sim K_{m}$, where $K_{m}$ is the momentum turbulent exchange coefficient. [An attempt to develop a quantitative theory of the Phillips (1977) type interaction has been undertaken by Ostrovsky and Zaborskikh (1996); in particular, they found a considerable inhibiting of long waves by the near-surface turbulence, which remains finite at $k \rightarrow 0$.]

During calm periods, there is a "barrier" layer in the western Pacific warm pool (Lukas and Lindstrom 1991), isolating the upper ocean from deeper layers $\left(K_{\varphi} \approx K_{m}\right.$ $\approx 0$ ); according to (A1), the turbulent flux $\mathbf{J}$ of the wave energy is also small. During westerly wind bursts the barrier layer in the warm pool area disappears: The ver- tical mixing coefficient increases; the vertical flux of the wave energy too. The upper ocean turbulence then absorbs the internal wave energy from the mixed layer [as well from deeper layers, according to (A1)], thus reducing the horizontal variability both within the mixed layer and below it.

\section{APPENDIX B}

\section{Spectral Model of Internal Waves}

We employ an "equatorial" version of Garrett and Munk spectral model of internal waves, taking in mind its possible limitations near the boundaries (Pinkel 1975). The spectra of vertical displacement and horizontal velocity are (Garrett and Munk 1981)

$$
\begin{aligned}
F_{\zeta}(\omega, j) & =b^{2} N_{0} N^{-1}\left(\omega^{2}-f^{2}\right) \omega^{-2} E(\omega, j), \\
F_{u}(\omega, j) & =F_{1}(\omega, j)+F_{2}(\omega, j) \\
& =b^{2} N_{0} N\left(\omega^{2}+f^{2}\right) \omega^{-2} E(\omega, j),
\end{aligned}
$$

where $j$ is the vertical mode number, $b \approx 1.3 \mathrm{~km}$ the $e$-folding scale of $N(z)$ with $N_{0} \approx 5.2 \times 10^{-3} \mathrm{~s}^{-1}$ the surface extrapolated buoyancy frequency, and $f$ the Coriolis frequency. The internal wave energy is assumed to be equally distributed in all horizontal directions so that only a single horizontal wavenumber, $k=\left(k_{1}^{2}+\right.$ $\left.k_{2}^{2}\right)^{1 / 2}$, is used. Here $E(\omega, j)$ is a dimensionless energy density that is factored as follows:

$$
\begin{gathered}
E(\omega, j)=B(\omega) H(j) E \\
B(\omega)=2 \pi^{-1} f_{0} \omega^{-1}\left(\omega^{2}-f^{2}\right)^{-1 / 2}, \\
\int_{f}^{N(z)} B(\omega) d \omega, \\
H(j)=\left(j^{2}+j_{*}^{2}\right)^{-1}\left(\sum_{1}^{\infty}\left(j^{2}+j_{*}^{2}\right)^{-1}\right)^{-1}, \\
\sum_{1}^{\infty} H(j)=1,
\end{gathered}
$$

where $j_{*}=3$ is a mode scale number and $E=6.3 \times$ $10^{-5}$ is a dimensionless internal wave "energy parameter." There is some evidence that the spectral energy density is independent of latitude; following the recommendation of Garrett and Munk (1981), we use $f_{0}$ $=7.3 \times 10^{-5} \mathrm{~s}^{-1}$, which is the Coriolis frequency at $30^{\circ}$ lat.

\section{a. The frequency spectrum $S_{\zeta}(\omega)$}

The spectrum is calculated from (B1), (B3), and (B4) by the mode summation 


$$
\begin{aligned}
S_{\zeta} & =\sum_{j=1}^{j_{u}} F(\omega, j) \\
& =2 \pi^{-1} b^{2} N_{0} N^{-1} f_{0} \omega^{-2}\left(1-f^{2} \omega^{-2}\right)^{1 / 2} E \sum_{j=1}^{j_{u}} H(j),
\end{aligned}
$$

where subscript $u$ denotes the upper mode.

\section{$b$. The wavenumber spectrum $E_{\zeta}(k)$}

The transfer from $(\omega, j)$ to $(k, j)$ space is accomplished by setting $F_{\zeta}(k, j) d k=F_{\zeta}(\omega, j) d \omega$. For slowly varying $N(z)$, in accord with WKB approximation,

$$
k N_{0}\left(\omega^{2}-f^{2}\right)^{-1 / 2} \approx \pi b^{-1} j,
$$

where we ignore the situation near the buoyancy turning frequency. From (B6),

$$
\frac{d \omega}{d k}=\left(\frac{N_{0} b}{\pi}\right) j^{-1} k\left[\left(\frac{\pi f j}{N b}\right)^{2}+k^{2}\right]^{-1 / 2} .
$$

Taking into account (B7), the spectra of vertical displacement (B1) can be converted into

$F_{\zeta}(k, j)=2 b f_{0} E N^{-1} k^{-2} j^{-1} H(j)\left[1+\left(\frac{\pi f j}{N_{0} b}\right)^{2} k^{-2}\right]^{-2}$,

where $H(j)$ is determined by (B4). The mode summation results in

$$
\begin{aligned}
E_{\zeta}(k) & =\sum_{j=1}^{j_{u}} F_{\zeta}(k, j) \\
& =2 b f_{0} E N^{-1} k^{-2} \sum_{j=1}^{j_{u}} j^{-1} H(j)\left[1+\left(\frac{\pi f j}{N_{0} b}\right)^{2} k^{-2}\right]^{-2} .
\end{aligned}
$$

\section{REFERENCES}

Anderson, S. P., R. A. Weller, and R. Lukas, 1996: Surface forcing and the mixed layer in the warm pool: Observations and 1D results. J. Climate, 9, 3056-3085.

Antonia, R. A., A. J. Chambers, C. A. Friehe, and C. W. Van Atta, 1979: Temperature ramps in the atmospheric surface layer. $J$. Atmos. Sci., 36, 99-108.

Barenblatt, G. I., 1978: Strong interaction of gravity waves and turbulence. Izv. Acad. Sci. USSR, Atmos. Oceanic Phys., 13, 581583.

Benilov, A. Yu., 1973: Generation of ocean turbulence by surface waves. Izv. Acad. Sci. USSR, Atmos. Oceanic Phys., 9, 160-164.

Boyd, T. J., D. S. Luther, R. A. Knox, and C. Hendershott, 1993: High-frequency internal waves in the strongly sheared currents of the upper equatorial Pacific: Observations and a simple spectral model. J. Geophys. Res., 98, 18 089-18 107.

Brainerd, K. E., and M. C. Gregg, 1997: Turbulence and stratification on the TOGA-COARE microstructure-pilot cruise. J. Geophys. Res., 102, $10437-10455$.

Chereskin, T. K., J. N. Moum, P. J. Stabeno, D. R. Caldwell, and C. Paulson, 1986: Fine-scale variability at $140^{\circ} \mathrm{W}$ in the equatorial Pacific. J. Geophys. Res., 91, 12 887-12 897.
Emery, W. J., and R. E. Thompson, 1998: Data Analysis Methods in Physical Oceanography. Pergamon Press, 634 pp.

Eriksen, C. C., 1988: Variability in the upper-ocean internal wave field at a Sargasso Sea site. J. Phys. Oceanogr., 18, 1459-1513.

Feng, M., M. A. Merrifield, R. Pinkel, P. Hacker, A. J. Plueddemann, E. Firing, R. Lukas, and C. Eriksen, 1998: Semidiurnal tides observed in the western equatorial Pacific during TOGA COARE. J. Geophys. Res., 103, 10 253-10 272.

Firing, E., J. Ranada, and P. Caldwell, 1995: Access to the CODAS high-resolution ship-board ADCP data sets. [Available from Hawaii NODC Liaison Office, Dept. of Oceanography, 1000 Pope Rd., University of Hawaii, Honolulu, HI 96822.]

Garrett, C., and W. Munk, 1972: Space-time scales of internal waves. Geophys. Fluid Dyn., 2, 225-264.

Huyer, A., P. M. Kosro, R. Lukas, and P. Hacker, 1997: Upper-ocean thermohaline fields near $2^{\circ} \mathrm{S}, 156^{\circ} \mathrm{N}$ during TOGA COARE, November 1992 to February 1993. J. Geophys. Res., 102, $12749-$ 12784.

Konyaev, K. V., 1990: Spectral Analysis of Physical Oceanographic Data. A. A. Balkema, 200 pp.

Lukas, R., 1990: Freshwater input to the western equatorial Pacific Ocean and air-sea interaction. Proc. US-PRC Int. TOGA Symp., Beijing, China, China Ocean Press, 305-327.

— torial Pacific Ocean. J. Geophys. Res., 96 (Suppl.), 3343-3357.

, P. Hacker, M. Mao, E. Firing, A. Huyer, and P. M. Kosro, 1995: Upper ocean currents in the intensive flux array during TOGA COARE. Proc. TOGA 95 Conf., Melbourne, Australia, WCRP91, WMO/TD 717, 542-546.

Moore, A. M., and R. Kleeman, 1996: The dynamics of error growth and predictability in a coupled model of ENSO. Quart. J. Roy. Meteor. Soc., 122, 1405-1446.

Müller, P., and D. J. Olbers, 1975: On the dynamics of internal waves in the deep ocean. J. Geophys. Res., 80, 3848-3860.

- _ - and J. Willebrand, 1978: The Iwex spectrum. J. Geophys. Res., 83, 479-500.

Munk, W., 1981: Internal waves and small scale processes. Evolution of Physical Oceanography, B. A. Warren and C. Wunsch, Eds., The MIT Press, 264-291.

Oppenheim, A. V., and R. W. Schafer, 1975: Digital Signal Processing. Prentice-Hall, 585 pp.

Ostrovsky, L. A., and D. V. Zaborskikh, 1996: Damping of internal gravity waves by small-scale turbulence. J. Phys. Oceanogr., 26, 388-397.

Phillips, O. M., 1977: The Dynamics of the Upper Ocean. 2d ed. Cambridge University Press, $336 \mathrm{pp}$.

Picaut, J., A. J. Busalachi, M. J. McPhaden, L. Gourdeau, F. I. Gonzalez, and E. C. Hackert, 1995: Open-ocean validation of TOPEX/Poseidon sea level in the western equatorial Pacific. J. Geophys. Res., 100, 25 109-25 127.

Pinkel, R., 1975: Upper ocean internal wave observations from FLIP. J. Geophys. Res., 80, 3892-3910.

- M. Merrifield, M. McPhaden, J. Picaut, S. Rutledge, D. Siegel, and L. Washburn, 1997: Solitary waves in the western equatorial Pacific Ocean. Geophys. Res. Lett., 24, 1603-1606.

Plueddemann, A. J., and Coauthors, 1993: TOGA COARE mooring deployment, check-out, the recovery cruises. Woods Hole Oceanographic Institution Tech. Rep. WHOI-93-30, $54 \mathrm{pp}$. [Available from Woods Hole Oceanographic Institution, Woods Hole, MA 02543.]

Rabiner, L. R., and B. Gould, 1975: Theory and Application of Digital Signal Processing. Prentice-Hall, 858 pp.

Richards, K. J., and R. T. Pollard, 1991: Structure of the upper ocean in the western equatorial Pacific. Nature, 350, 48-50.

Smyth, W. D., D. Hebert, and J. N. Moum, 1996a: Local ocean response to a multiphase westerly wind burst, Part 1: The dynamic response. J. Geophys. Res., 101, 22 495-22 512.

,-- , and — 1996b: Local ocean response to a multiphase westerly wind burst. Part 2: Thermal and freshwater response. J. Geophys. Res., 101, 22 513-22 533. 
Soloviev, A. V., 1990: Coherent structure at the ocean surface in the convectively unstable conditions. Nature, 346, 157-160.

— surface layer of the western equatorial Pacific warm pool. DeepSea Res., 44, 1055-1076.

— N. V. Vershinsky, and V. A. Bezverkhnii, 1988: Small-scale turbulence measurements in the thin surface layer of the ocean. Deep-Sea Res., 35, 1859-1874.

Taylor, G. I., 1938: The spectrum of turbulence. Proc. Roy. Soc. London, A164, 476-490.

Thorpe, S. A., 1985: Small-scale processes in the upper ocean boundary layer. Nature, 318, 519-522.
Webster, P. J., and R. Lukas, 1992: TOGA COARE: The Coupled Ocean-Atmosphere Response Experiment. Bull. Amer. Meteor. Soc., 73, 1377-1416.

Weller, R. A., and S. P. Anderson, 1996: Surface meteorology and air-sea fluxes in the western equatorial Pacific warm pool during the TOGA Coupled Ocean-Atmosphere Response Experiment. J. Climate, 9, 1959-1990.

Wijesekera, H. W., and M. G. Gregg, 1996: Surface layer response to weak winds, westerly bursts, and rain squalls in the western Pacific Warm Pool. J. Geophys. Res., 101, 977-997.

- C. A. Paulson, and A. Huyer, 1999: The effect of rainfall on the surface layer during a westerly wind burst in the western equatorial Pacific. J. Phys. Oceanogr., 29, 612-632. 